\title{
Vertical Sampling in Tree Canopies for Halyomorpha halys (Hemiptera: Pentatomidae) Life Stages and its Egg Parasitoid, Trissolcus japonicus (Hymenoptera: Scelionidae)
}

\author{
Nicole F. Quinn, ${ }^{1,5}$ Elijah J. Talamas, ${ }^{2}$ Angelita L. Acebes-Doria, ${ }^{3}$ Tracy C. Leskey, ${ }^{4}$ and \\ J. Christopher Bergh ${ }^{1}$ \\ 'Department of Entomology, Alson H. Smith Jr. Agricultural Research and Extension Center, Virginia Tech, Winchester, VA 22602, \\ ${ }^{2}$ Division of Plant Industry, Florida Department of Agriculture and Consumer Services, Gainesville, FL 32608, ${ }^{3}$ Department of \\ Entomology, University of Georgia, Tifton, GA 31793, ${ }^{4}$ Appalachian Fruit Research Station, USDA ARS, Kearneysville, WV 25430, and \\ ${ }^{5}$ Corresponding author, e-mail: quinni01@vt.edu
}

Subject Editor: Matthew Ginzel

Received 20 September 2018; Editorial decision 12 November 2018

\begin{abstract}
The brown marmorated stink bug, Halyomorpha halys (Stål) (Hemiptera: Pentatomidae), is an invasive agricultural and nuisance pest that has established across much of the United States and caused significant crop losses in the Mid-Atlantic region. While it has been monitored extensively using ground-deployed pheromone traps, the vertical distribution of its life stages in the canopy of wild tree hosts has not been examined. In Virginia, small pyramid traps baited with 'low-dose' $H$. halys pheromone lures were deployed via a pulley system at the lower, mid-, and upper canopy of female tree of heaven (Ailanthus altissima (Mill.) Swingle) in 2016 and 2017 and male A. altissima and hackberry (Celtis occidentalis L.) in 2017. Weekly captures of adults and nymphs were recorded throughout each season. Each year, additional female $A$. altissima trees were felled during the two main periods of $H$. halys oviposition. The number and relative locations of all pentatomid egg masses found on foliage were recorded and any parasitoids that emerged from them were identified. Halyomorpha halys adults and nymphs were captured in greatest numbers in upper canopy traps and in lowest numbers in traps near the tree base. More $H$. halys egg masses were collected from mid-canopy than from the lower or upper canopy. The adventive egg parasitoid, Trissolcus japonicus (Ashmead) (Hymenoptera: Scelionidae), emerged most frequently from egg masses found at mid-canopy and was not recovered from those in the lower canopy. Results are discussed in relation to the foraging ecology of $H$. halys and its natural enemies, including TT. japonicus.
\end{abstract}

Key words: brown marmorated stink bug, biological control, parasitoid, invasive species

Halyomorpha halys (Stål) (Hemiptera: Pentatomidae) is an invasive pest from Asia (Hoebeke and Carter 2003) that feeds or reproduces on many cultivated and wild plants (www.stopbmsb.org). A widespread outbreak of $H$. halys in the Mid-Atlantic region of the United States in 2010 resulted in losses of over $\$ 37$ million to the apple crop and severe impacts to many peach orchards (Leskey et al. 2012). Given its broad host range, high mobility (Lee et al. 2014, Wiman et al. 2015, Lee and Leskey 2015), and propensity to 'hitchhike' in human conveyances, $H$. halys has now been detected or established in 44 states, four Canadian provinces (www.stopbmsb.org; accessed 12 March 2018), and several countries abroad (Leskey and Nielsen 2018).

Halyomorpha halys is not known to reside permanently in any crop, but moves into crops from its many wild hosts (Bakken et al. 2015). It is considered a perimeter-driven pest, and injury from its feeding is often greatest at crop borders next to wooded areas (Leskey et al. 2012, Joseph et al. 2014, Venugopal et al. 2015, Bergmann et al. 2016). Given its wide distribution and mobility in the landscape, insecticide applications can reduce $H$. halys injury to crops but likely do not have a substantial effect on its pest pressure overall. Most of the effective insecticides for managing $H$. halys injury to crops are toxic to natural enemies, resulting in disruption of integrated pest management programs and frequent outbreaks of secondary pests (Rice et al. 2014, Leskey and Nielsen 2018). Thus, effective biological control of $H$. halys in non-crop habitats is considered a key element of its sustainable management.

In the United States, numerous native parasitoids and predators that attack $H$. halys have been identified, but have not regulated its populations adequately (Abram et al. 2017). During the summer of 
2014, an adventive population of the Asian parasitoid of $H$. halys eggs, Trissolcus japonicus (Ashmead) (Hymenoptera: Scelionidae), was detected from samples collected in Beltsville, MD (Talamas et al. 2015a). Subsequent detections have occurred in the Mid-Atlantic and Pacific Northwest (reviewed in Leskey and Nielsen 2018). In Frederick County, VA, T. japonicus has been detected annually since 2015 (Quinn, unpublished data). Given the important role of T. japonicus in regulating $H$. halys in its native Asian range (Yang et al. 2009, Zhang et al. 2017), this significant development may result in improved biocontrol services in the United States (Abram et al. 2017).

Typically, pheromone-based monitoring of $H$. halys has used ground-deployed traps (Leskey et al. 2015, Morrison et al. 2015). However, anecdotal and experimental observations suggest that $H$. halys activity may be most abundant in the upper canopy of host trees. B. D. Short (USDA ARS, personal communication) observed high numbers of $H$. halys and appreciable feeding injury from it at the top of tree of heaven, Ailanthus altissima (Mill.) Swingle (Sapindales: Simbaroubaceae), and Joseph et al. (2014) recorded greatest fruit injury from $H$. halys at the top of apple trees in commercial orchards. If $H$. halys density is stratified vertically in the host tree canopy, the distribution and density of its egg masses, and thus of its egg parasitoids, may also be similarly stratified. Understanding these distributions would greatly enhance our capacity to monitor the presence, abundance, and impact of its egg parasitoids, including T. japonicus.

This study presents data from trapping and destructive sampling studies that examined: 1 ) the vertical distribution of $H$. halys captures in pheromone traps, 2) the vertical distribution of its egg masses, and 3) the predation and parasitization of these egg masses and the parasitoid species recovered from them.

\section{Materials and Methods}

\section{Trapping Sites and Tree Hosts}

All studies were conducted in Frederick County, VA. The host trees used for trapping were located at Virginia Tech's Alson H. Smith, Jr. Agricultural Research and Extension Center (AREC) near Winchester, VA $(39.112867,-78.284029)$ and at three commercial fruit orchards within $20 \mathrm{~km}$ of the AREC. Given that tree of heaven was the most common deciduous tree species in the local landscape (Acebes-Doria et al. 2017) and that it can harbor large populations of $H$. halys in the eastern United States (Bakken et al. 2015) (Fig. 1), female tree of heaven $(n=5)$ were selected for sampling in 2016 and 2017, using the same trees each year. In 2017, male tree of heaven $(n=5)$ and hackberry, Celtis occidentalis L. (Rosales: Cannabaceae) $(n=5)$ were also sampled. Hackberry is a host of $H$. halys (www.stopbmsb.org) and was the second most common deciduous tree species recorded at the woodland edge in this region (Acebes-Doria et al. 2017). All trees were located at the woods edge adjacent to experimental or commercial apple and peach orchards. Each sample tree was $\geq 20 \mathrm{~m}$ from other trees of the same sex or species and $\geq 101 \mathrm{~m}$ from other trees having traps. Trees of similar height $(9.2 \mathrm{~m} \pm 0.29 \mathrm{SE}), \mathrm{DBH}(24.1 \mathrm{~cm} \pm 1.3 \mathrm{SEM})$, and architecture (i.e., mostly upright, with branching along most of the trunk), were selected. All trees bore fruit during the season, with the exception of male tree of heaven.

\section{PheromoneTrap Transects}

Professional arborists inserted an eye bolt near the top and bottom of the trunk of each tree. A pulley system was created by running a rope through these and attaching the ends, creating a loop that enabled

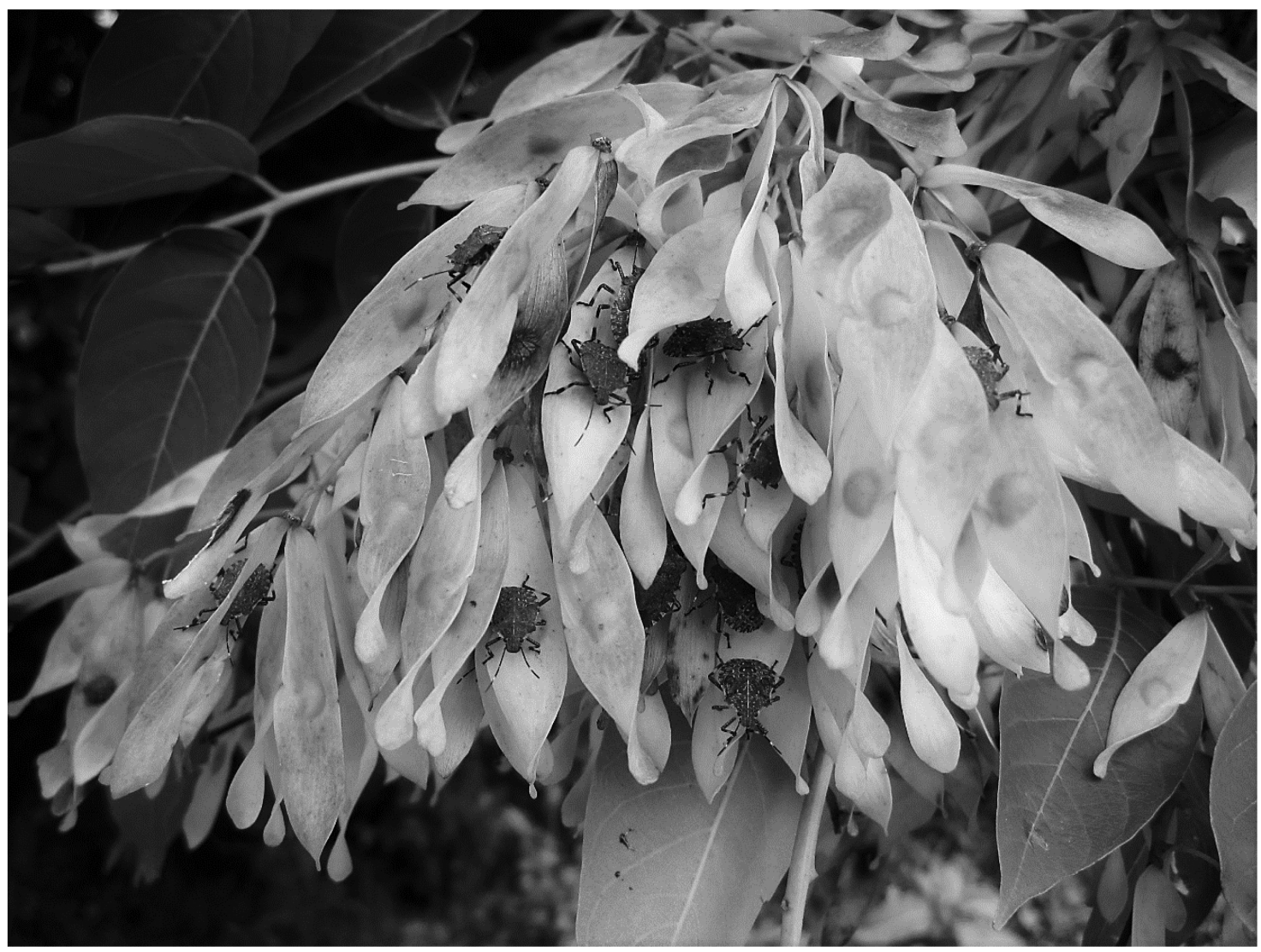

Fig. 1. Nymphal H. halys on the samaras of a female tree of heaven (Ailanthus altissima) at Virginia Tech's research station near Winchester, VA. Photo credit: J. C. Bergh. 
raising and lowering the traps easily for sampling along the length of the trunk. The rope was attached to the bottom eye bolt using a carabiner, and the vertical distance between the top and bottom bolt was measured, enabling even spacing of traps. Three $61 \mathrm{~cm}$ tall pyramid traps (Dead-Inn, AgBio, Westminster, CO) were deployed in each tree (Fig. 2A). These were baited with a low-dose residential $H$. halys lure containing its aggregation pheromone, $(3 S, 6 S, 7 R, 10 S)$ 10,11-epoxy-1-bisabolen-3-ol and (3R,6S,7R,10S)-10,11-epoxy-1bisabolen-3-ol (Khrimian et al. 2014) and its pheromone synergist, methyl (2E,4E,6Z)-decatrienoate (MDT) (Weber et al 2014), as well as the main component of the aggregation pheromone of Euschistus spp., methyl decadienoate, at loadings of $17 \mathrm{mg}, 17 \mathrm{mg}$, and $7.5 \mathrm{mg}$, respectively (AgBio, Westminster, $\mathrm{CO}$ ). Along with lures, half of a dichlorvos-impregnated strip (Vaportape, Hercon, York, PA) hung within the collection jar atop the trap served as the killing agent. Lures and dichlorvos strips were replaced at 14-d intervals, according to manufacturer specifications and field data (Joseph et al. 2013). The bottom trap was attached to the tree trunk at $1.04 \pm 0.08 \mathrm{SE} \mathrm{m}$ above the ground, and the two other traps were attached to the rope and positioned, respectively, at the approximate midpoint between the upper and lower bolts and just below the upper bolt (Fig. 2A and B). Traps at mid- and upper canopy, respectively, were $4.30 \pm 0.39$ $\mathrm{SE} m$ and $8.60 \pm 0.79 \mathrm{SE} \mathrm{m}$ above the bottom traps. The number of $H$. halys adults and nymphs captured in each trap was recorded weekly from mid-April until mid-October.

\section{Destructive Sampling}

Mature female tree of heaven growing at the edge of woods next to three commercial fruit orchards within $12 \mathrm{~km}$ of the AREC were chosen, using the same selection criteria described above. Trees selected for destructive sampling $\geq 230 \mathrm{~m}$ away from trees with pheromone traps. In 2016, trees were felled between 21 and 23 June $(n=5)$ and between 2 and 5 August $(n=5)$, and in 2017, trees were felled between 20 and 21 June $(n=5)$ and 8-9 August $(n=5)$. The June and August samples occurred within the predicted periods of oviposition by the overwintering and summer generations, respectively, of adult $H$. halys (Nielsen et al. 2016). After felling, total tree height, height of each branch at its growth point from the trunk, and stump circumference $(\sim 1 \mathrm{~m}$ above the ground) were measured, and all branches were flagged and numbered. The mean $( \pm$ SE) height of the felled trees in 2016 and 2017, respectively, was $9.9 \pm 0.47 \mathrm{~m}$ and $10.16 \pm 3.22 \mathrm{~m}$. The number of fruiting structures (samaras) was also recorded. All leaves were inspected, and all pentatomid egg masses found were collected and identified using visual appearance and comparisons with the field guide of Herbert et al. (2014). For each egg mass found, the length of the branch on which it occurred, its linear distance from the trunk (based on branch length), and its approximate height were recorded. The foliage from each branch was placed in paper landscape bags and air-dried in a greenhouse for determination of foliar biomass.
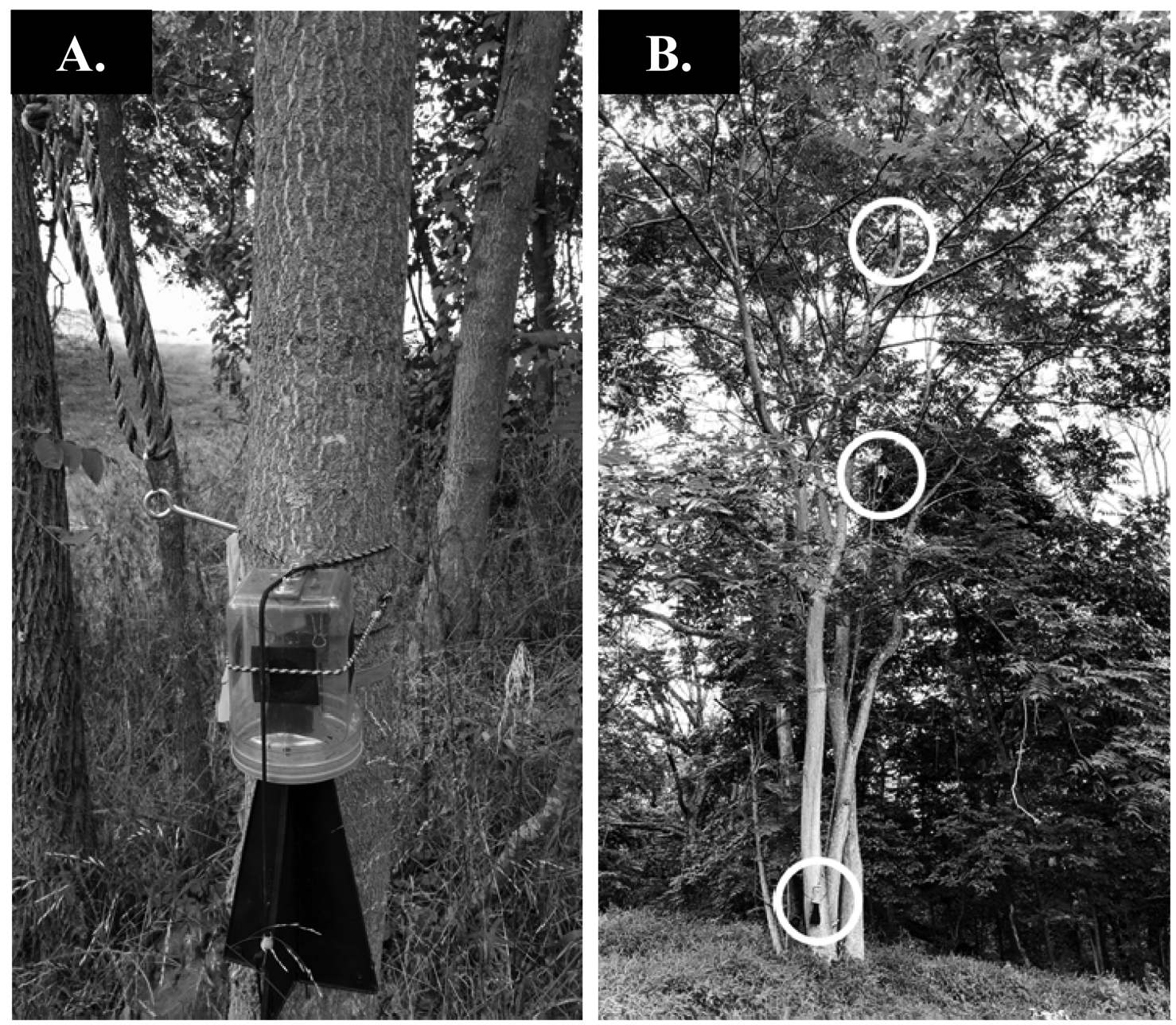

Fig. 2. (A) Pheromone-baited pyramid trap deployed in tree of heaven (Ailanthus altissima), (B) pheromone-baited pyramid traps (indicated by circles) at the upper, middle, and lower canopy of female tree of heaven (Ailanthus altissima) near Winchester, VA. 
Egg masses were held individually in small Petri dishes in a controlled-environment chamber at $25^{\circ} \mathrm{C}$ and a $16: 8$ (L:D) h photoperiod. The eggs in each mass were counted and categorized as to whether they were intact, had yielded nymphs previously (based on the presence of an egg burster), had yielded parasitoids previously (based on the presence of circular parasitoid emergence holes), or had been preyed upon, as per Morrison et al. (2016). Masses with intact eggs were monitored daily for emergence of $H$. halys nymphs or parasitoids. Specimens of all parasitoids that emerged were identified using the keys of Johnson (1984), Talamas et al. (2015b), and Burks (1967).

\section{Statistical Analysis}

Data analyses used SAS 9.4 (SAS Institute, Cary, NC; SAS Institute Inc 2018) and $\alpha=0.05$. For each year, captures of $H$. halys from vertical trap transects were log transformed and compared among trap locations (upper, mid, or lower canopy) and tree type (female tree of heaven, male tree of heaven, or hackberry) using generalized linear mixed models (GLMMs) with Laplace approximation and log-normal distribution, with trap location as the main effect. The interaction of trap location and sampling date were nested within sample tree as random effects. From the destructive sampling, Kendall's Tau-b correlation coefficients were used to examine the relationships between the number of pentatomid egg masses collected, T. japonicus detection, tree height, branch height, branch length, tree circumferences, linear distance from trunk, dry foliar biomass, and number of samaras.

\section{Results}

\section{Pheromone TrapTransects}

In 2016, there was a significant effect of trap location on mean weekly captures of $H$. halys adults $\left(F_{2,121}=39.87, P<0.01\right)$ and nymphs $\left(F_{2,59}=35.61, P<0.01\right)$ in female tree of heaven. Adult captures differed significantly among the three canopy locations, with highest and lowest numbers in the upper and lower traps, respectively (Fig. 3). Captures of nymphs were significantly greater in the upper canopy than in mid- or lower canopy, which did not differ significantly from each other (Fig. 3).
In 2017, no significant effect of tree species on mean weekly captures of adults $\left(F_{2,296}=0.085, P=0.43\right)$ or nymphs $\left(F_{2,141}=0.33\right.$, $P>0.05$ ) (Fig. 4A); therefore, host species was excluded from the model and captures were compared by canopy location. Captures of adults in the upper canopy were significantly greater than in the mid- and lower canopy, which did not differ significantly from each other $\left(F_{2,296}=55.81, P<0.05\right)$ (Fig. 4B). Similarly, nymph captures were significantly greater in the upper canopy than in the mid- and lower canopy, which did not differ $\left(F_{2,141}=2.40, P>0.05\right)$ (Fig. 4B).

\section{Destructive Sampling: Egg Masses}

In total, 38 and 20 pentatomid egg masses were collected in 2016 and 2017, respectively. All egg masses were recovered from the underside of leaves. Fifty-one $(87.9 \%)$ of these were identified as $H$. halys, with the remainder identified as Chinavia hilaris (Say) (Hemiptera: Pentatomidae) $(n=2)$, Nezara viridula (L.) (Hemiptera: Pentatomidae) $(n=2)$, Euschistus spp. (Hemiptera: Pentatomidae) $(n=2)$, and Podisus maculiventris (Say) (Hemiptera: Pentatomidae) ( $n=1)$. Halymorpha halys egg masses were found in eight of the 10 trees in 2016 (range $=1$ to 8 per tree) and in six of the 10 trees (range $=1$ to 6 per tree) in 2017 .

The majority $(58.8 \%)$ of the $51 \mathrm{H}$. halys egg masses were from the middle third of the canopy $(n=30)$, with essentially equal numbers from the upper $(n=11)$ and lower $(n=10)$ thirds. Of the seven variables measured from the felled trees (Table 1 ), the number of $H$. halys egg masses found in 2016 was significantly correlated with branch length $(r=0.20, n=157, P<0.001)$, linear distance from the trunk $(r=0.24, n=157, P=0.045)$ and foliar biomass $(r=0.29, n=157$, $P<0.0001)$, and with branch length $(r=0.20, n=122, P=0.007)$ in 2017. A marginally significant correlation was found between egg masses and branch height in $2017(r=0.14, n=126, P=0.05)$.

\section{Destructive Sampling: Parasitization and Predation}

All $51 \mathrm{H}$. halys egg masses collected in 2016 and 2017 produced nymphs or parasitoids before and/or after collection, or showed signs of predation. Twenty-four $(47.1 \%)$ produced only nymphs, 11 $(21.6 \%)$ yielded only parasitoids, and nine $(17.6 \%)$ showed indications of predation only. The remainder produced both nymphs and parasitoids $(n=3 ; 5.9 \%)$, yielded nymphs and showed some

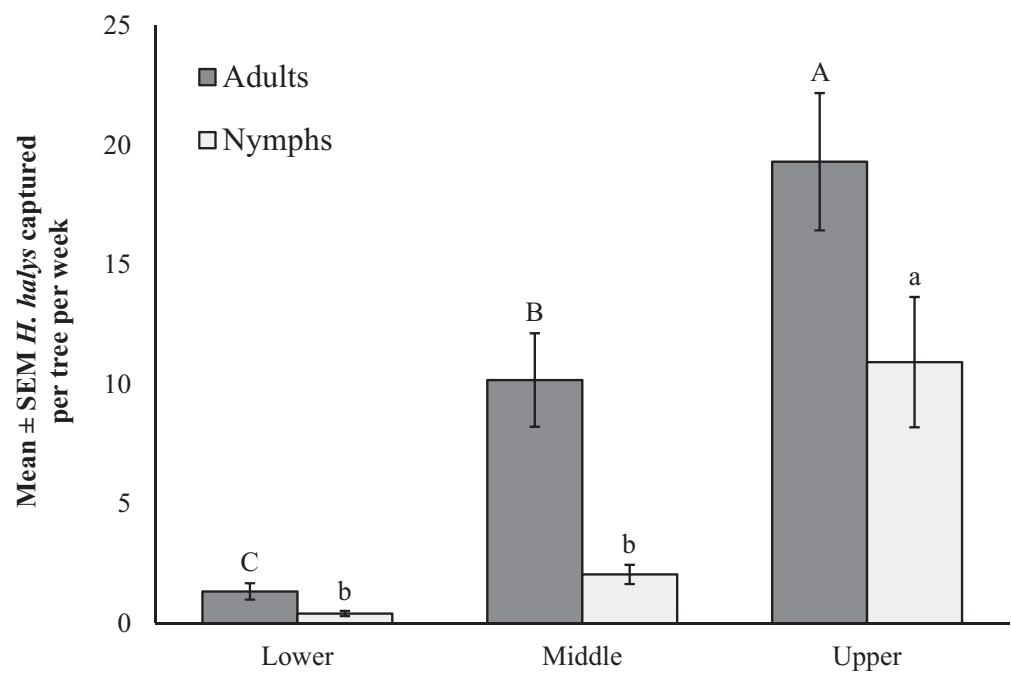

Canopy Location

Fig. 3. Mean $( \pm$ SE) weekly captures of $H$. halys adults and nymphs in pheromone-baited pyramid traps at lower, middle, and upper canopy locations in female Ailanthus altissima in 2016. Bars with the same upper or lower case letter are not significantly different. 

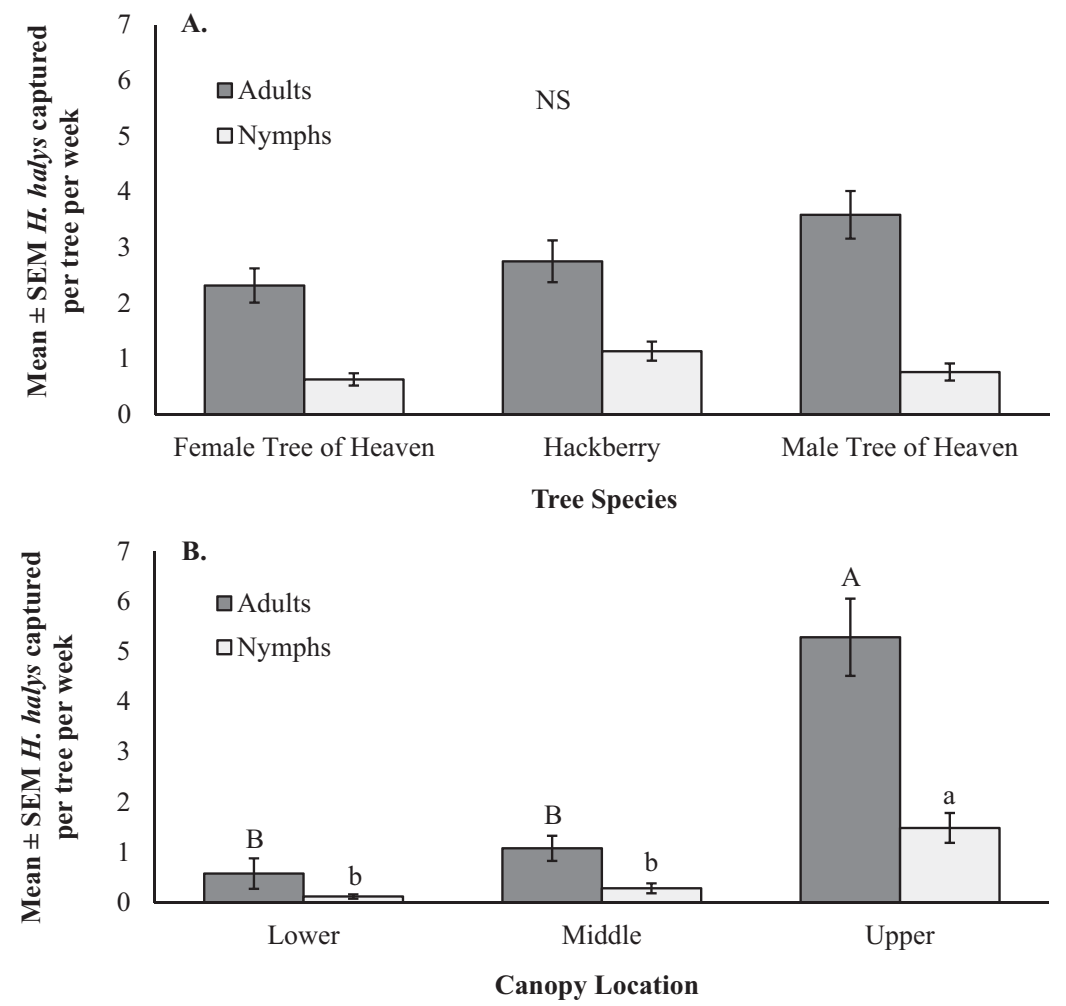

Fig. 4. Mean $( \pm$ SE) weekly captures of $H$. halys adults and nymphs in pheromone-baited pyramid traps at lower, middle, and upper canopy locations in 2017 by (A) tree species and (B) canopy location.

Table 1. Kendall Tau-b correlation coefficient values for the relationship between measurements from felled female tree of heaven, $H$. halys egg masses, and T. japonicus detections in 2016 and 2017

\begin{tabular}{|c|c|c|c|c|}
\hline \multirow[t]{2}{*}{ Measurement } & \multicolumn{2}{|c|}{2016} & \multicolumn{2}{|c|}{2017} \\
\hline & Number of egg masses & T. japonicus detections & Number of egg masses & T. japonicus detections \\
\hline Tree height & 0.07 & $0.15^{* *}$ & 0.11 & 0.08 \\
\hline Branch height & 0.01 & 0.12 & $0.14^{*}$ & $0.15 * *$ \\
\hline Branch length & $0.20 *$ & 0.12 & $0.20 * *$ & 0.04 \\
\hline Tree circumference & 0.09 & 0.01 & 0.002 & 0.07 \\
\hline Linear distance of egg mass from trunk & $0.24 * *$ & 0.07 & 0.38 & 0.14 \\
\hline Foliar biomass by branch & $0.29 * * * *$ & $0.26 * *$ & 0.0004 & 0.09 \\
\hline Number of samaras & 0.11 & 0.13 & 0.11 & 0.03 \\
\hline
\end{tabular}

$$
\text { *P }=0.05 ; * * P<0.05 ; * * P<0.01 ; * * * P<0.001 ; * * * * P<0.0001 .
$$

degree of predation $(n=3 ; 5.9 \%)$, or showed both predation and produced parasitoids $(n=1 ; 2.0 \%)$. Of the 14 egg masses from which adult parasitoids emerged in the laboratory, eight yielded T. japonicus adults $(99.1 \pm 0.9 \mathrm{SE} \%$ eggs parasitized). These were distributed among six trees (range $=1$ to 3 per tree), with six egg masses from the middle third of the canopy and the remaining two from the upper third. Detections of T. japonicus were positively correlated with tree height $(r=0.15, n=157, P=0.03)$ and dry foliar biomass $(r=0.26, n=117, P=0.008)$ in 2016, and with branch height $(r=0.15, n=126, P=0.04)$ in 2017 (Table 1). Six $H$. halys egg masses produced adults of native parasitoid species, including Telenomus podisi Ashmead (Hymenoptera: Scelionidae) ( $n=1 ; 88.5 \%$ eggs parasitized), Pteromalidae (Hymenoptera) $(n=1$; $32.1 \%$ eggs parasitized), Trissolcus brochymenae (Ashmead) (Hymenoptera: Scelionidae) ( $n=1 ; 85.7 \%$ eggs parasitized), and Anastatus spp. (Motuschulsky) (Hymenoptera: Eupelmidae) $(n=3$; $97.4 \pm 1.8 \mathrm{SE} \%$ eggs parasitized). Two of the H. halys egg masses that yielded Anastatus spp. were collected from the lower third of the canopy, otherwise all other masses yielding native parasitoids were found in mid-canopy. Of the native pentatomid egg masses collected, the Podisus maculiventris egg mass produced Anastatus spp., one Euschistus servus (Say) egg mass yielded Te. podisi, one C. hilaris egg mass produced Anastatus reduvii (Howard), and neither N. viridula egg mass was parasitized. Egg masses showing evidence of complete or partial predation ( $\geq 1$ predated egg; $n=13$ ) had $81.4 \pm 7.9$ SE \% eggs preyed upon.

\section{Discussion}

Detection of an adventive population of T. japonicus in Maryland in 2014 (Talamas et al. 2015a, Herlihy et al. 2016), and subsequent detections elsewhere in the United States (Leskey and Nielsen 2018), highlighted the need to develop efficient and effective sampling protocols to track its geographic distribution, spread, and population 
growth. Thus, information about the foraging ecology and distribution of both $H$. halys and T. japonicus in the canopy of $H$. halys host trees are of critical importance. Previously, the only information about the distribution of $H$. halys adults and nymphs in the canopy was from anecdotal observations suggesting a higher density in the upper portion of wild hosts. Furthermore, there was no information on the distribution of $H$. halys egg masses, the resource for T. japon$i$ icus, in the tree. We hypothesized that the distribution of $H$. halys would reflect the distribution of its egg masses and therefore the distribution of T. japonicus detections from eggs. Using captures of $H$. halys adults and nymphs in pheromone traps as a proxy for its vertical distribution in known tree hosts, our results indicated that these life stages were most abundant in the mid- and upper canopy. This finding was consistent between two tree species, the sexes of tree of heaven, and between sampling years, despite differences in the number of $H$. halys captured in female tree of heaven in 2016 and 2017. Conforming to these findings, destructive sampling from felled female tree of heaven revealed that $80 \%$ of the $H$. halys egg masses occurred in the mid- and upper canopy. Moreover, detections of T. japonicus occurred only from $H$. halys egg masses collected from the mid- and upper canopy.

In the absence of information about the distance over which $H$. halys responds to a point source of pheromone, we attempted to reduce the zone of attraction by using a commercially available 'residential' lure marketed for homeowner use that contained a lower loading of pheromone than lures used to monitor $H$. halys in agricultural systems. Admittedly, sampling $H$. halys adults and nymphs in the canopy using vertical transects of pheromone traps raises questions about the behavioral response of the insect to the lures. However, the spatial coincidence between captures in traps and the location of egg masses in trees without traps concurs with anecdotal observations of high density in the upper canopy (B. D. Short, personal communication) and experimental data showing greatest fruit injury in the upper canopy of apple trees (Joseph et al. 2014). Moreover, laboratory and field experiments by AcebesDoria et al. $(2016,2017)$ showed that $H$. halys nymphs were negatively gravitactic and positively phototactic, and were captured in greater numbers walking up versus down tree trunks. Euschistus servus, a common native stink bug pest of many crops, was also captured in greater numbers in pheromone traps in the upper canopy of pecan trees than in other tree locations (Cottrell et al. 2000). Owens et al. (2013) reported that approximately $80 \%$ of the population of C. hilaris and E. servus were located in the upper canopy of mature soybean plants, independent of environmental conditions. Martinson et al. (2015) demonstrated that seasonal differences in $H$. halys abundance across a range of ornamental host trees were associated with host phenology; H. halys moved among the hosts in concert with the presence of fruiting structures during the season and were less abundant in experimentally de-fruited trees than in trees with fruit. Interestingly, despite differences in the presence of fruiting structures among the hosts used in the present study in 2017, no significant effect of plant species or sex on the number of $H$. halys adults or nymphs captured was observed.

Pentatomids exhibit differing preferences for oviposition sites. For example, E. servus oviposits more commonly on smaller cotton bolls, whereas N. viridula prefers larger bolls (Huang and Toews 2012). In general, $H$. halys is considered an arboreal species (Rice et al 2014), although it also feeds and oviposits on a range of plants and shrubs (www.stopbmsb.org) and typically deposits it eggs on the underside of host plant leaves (Nielsen and Hamilton 2009). We selected female tree of heaven as a model host for most of this work, given that its native range in Asia broadly overlaps with that of $H$. halys and that it very common host of $H$. halys in the eastern United States (Bakken et al. 2015, Acebes-Doria et al. 2017) that can support large populations of nymphs and adults (Bergh, personal observation; Fig. 1). Bakken et al. (2015) used visual inspection of foliage from the ground to document the presence and seasonal abundance of $H$. halys life stages, including egg masses, across a broad range of native and non-native hosts in the eastern United States, and showed that tree of heaven was among the hosts that supported the highest $H$. halys populations. In the present study, destructive sampling of felled female tree of heaven revealed that the preponderance of $H$. halys eggs masses were recovered from the mid- and upper canopy, suggesting that ground-based sampling may underestimate egg mass density.

Of the variables examined in relation to the specific location of the $H$. halys egg masses collected, only branch length showed a significant positive correlation with egg mass location in both years. The architecture of tree of heaven is quite different from many of the other common tree hosts of $H$. halys, producing foliage primarily near the end of branches, with long sections of branch that are sparsely foliated (Kowarik and Säumel 2007). Consequently, the outcomes of these analyses must be interpreted in context of the host trees in which sampling occurred. Furthermore, variation among felled trees in the numbers of egg masses collected and a low sample size overall ( 58 masses from 20 trees) likely affected the outcome of correlation analyses of the other variables.

As for $H$. halys, previous surveillance efforts for T. japonicus have also occurred primarily at ground level. In the United States, numerous researchers have detected it using sentinel or naturally laid $H$. halys egg masses in the lower canopy of host trees, and captured it in yellow sticky traps deployed in the lower canopy (Bergh, personal observation). In Asia, ground-based inspection of foliage for $H$. halys egg masses and deployment of sentinel eggs (Zhang et al. 2017) has also yielded T. japonicus. Hoelmer (personal communication) stated that, ' $\ldots$ in my Asia surveys, a large majority (2/3 to $3 / 4)$ of all $H$. halys egg masses discovered during ground-based searches were consistently $100 \%$ parasitized by T. japonicus. Clearly, T. japonicus can locate egg masses within lower strata of host plants, even if the majority of eggs are deposited higher in trees.' Unlike in its native Asian range, T. japonicus appears to be in early stages of establishment and spread in many parts of the United States, and new state records have occurred each year since its initial detection in Maryland. However, it has not yet been reported from all states where H. halys is established or from all regions within states where detections have occurred. Given that it likely remains a relatively rare species in many locations, our results suggest that sampling for T. japonicus in the lower tree canopy may affect the likelihood and frequency of its detection, particularly where its populations are small.

Although few parasitized $H$. halys egg masses were collected from felled trees, this is the first report of $H$. halys biological control in the United States in which T. japonicus was the predominant species, based on the percentage of egg masses attacked, and it appears to be establishing well in Frederick County, VA. For example, a female tree of heaven that was growing too close to one of the trees used in the trapping study was felled on 25 June 2017, and inspection of its foliage revealed seven $H$. halys egg masses, all of which subsequently yielded adults of T. japonicus. The even smaller number of $H$. halys egg masses from which native parasitoids emerged permits only species-level comparisons with previous research. Detection of Anastatus, Te. podisi, and Tr. brochymenae concurred with the findings from naturally laid $H$. halys egg masses collected from forest and other habitats (Abram et al. 2017, Dieckhoff et al. 2017, Jones et al. 2017), although other parasitoids were reported in those 
studies. Across these and the present study, Anastatus was the predominant native parasitoid. Dieckhoff et al. (2017) found that the same parasitoid complex attacked both naturally laid and sentinel H. halys egg masses. Using sentinel egg masses, Herlihy et al. (2016) and Cornelius et al. (2016) also recovered, among other species, Anastatus, Te. podisi, and Tr. brochymenae, with Anastatus reduvii being predominant in the former study.

More research on the biotic and abiotic factors that influence the foraging ecology of T. japonicus will be required to optimize the effectiveness and efficiency of sampling tools and protocols. Many parasitoids have demonstrated niche partitioning. In a case of spatial niche partitioning, different species of parasitoids of Mexican Anastrepha Shiner (Diptera: Tephritidae) differed in their vertical and horizontal distributions in the canopy of fruit trees (Sivinski et al. 1997). Other parasitoids attack hosts on different plant species at different rates. For example, Okuda and Yeargan (1988) observed higher levels of pentatomid egg parasitization by $T e$. podisi on alfalfa than hackberry, and the reverse for Trissolcus euschisti Ashmead. It is unknown whether kairomonal cues associated with $H$. halys egg masses attract T. japonicus from some distance, but Tognon et al. (2016) showed that two closely related species, Te. podisi and Trissolcus erugatus Johnson, were attracted to the egg adhesive of Euchistus conspersus Uhler. Recently, Boyle (2017) demonstrated that female T. japonicus responded to semiochemical cues left by the tarsi of gravid female $H$. halys, perhaps suggesting that the density of $H$. halys in the tree canopy may influence where T. japonicus forages most frequently. Similarly, Trissolcus basalis (Wollaston) exhibited increased movement speed and turning when exposed to substrate-borne kairomones from N. viridula (Colazza et al. 2014). Species of Trissolcus Ashmead are also able to discriminate between cues left by walking male and female pentatomids, spending significantly more time on substrates on which females had walked (Peri et al. 2013). Furthermore, feeding (Conti and Colazza 2012) and oviposition (Colazza et al. 2014) by pentatomids can induce plants to emit volatiles that attract egg parasitoids. Abiotic factors such as light intensity, temperature, and relative humidity may be directly affected by canopy density (Parker 1995) and may also influence T. japonicus foraging behavior.

Our findings add new insights into the foraging ecology of $H$. halys and T. japonicus in arboreal habitats. While the sampling methods used (i.e., deploying a pulley system and felling trees) may not be ideal for general adoption, they yielded important information that may guide the development of new and efficient methods to monitor T. japonicus in the canopy of $H$. halys host trees, toward documenting its habitat preferences and changes in its geographic distribution and relative abundance. As one example, Quinn (unpublished data) used yellow sticky traps atop bamboo poles that enabled trap deployment in the mid-canopy of host trees to show that the frequency of T. japonicus detections in Frederick County, VA, has increased markedly since the present studies were completed, boding well for its potential to impact $H$. halys populations.

\section{Acknowledgments}

We thank J. Engelman, G. Kerestesy, A. Wilson, N. Whalley, T. Garrett, E. Craig, and A. Hagen for their assistance. Thanks also to the growers who allowed us to cut the trees on their property. This research was supported by USDA ARS project \#8080-21000-024, USDA \#2016-51181-25409, and Specialty Crop Block grant \#12-25-B-1494 from the USDA via the Virginia Department of Agriculture and Consumer Services; and the Florida Department of Agriculture and Consumer Services.

\section{References Cited}

Abram, P. K., K. A. Hoelmer, A. Acebes-Doria, H. Andrews, E. H. Beers, J. C. Bergh, R. Bessin, D. Biddinger, P. Botch, M. L. Buffington, et al. 2017. Indigenous arthropod natural enemies of the invasive brown marmorated stink bug in North America and Europe. J. Pest Sci. 90: 1009-1020.

Acebes-Doria, A. L., T. C. Leskey, and J. C. Bergh. 2016. Development and comparison of trunk traps to monitor movement of Halyomorpha halys nymphs on host trees. Entomol. Exp. Appl. 158: 44-53.

Acebes-Doria, A. L., T. C. Leskey, and J. C. Bergh. 2017. Temporal and Directional patterns of nymphal Halyomorpha halys (Hemiptera: Pentatomidae) movement on the trunk of selected wild and fruit tree hosts in the mid-Atlantic Region. Environ. Entomol. 46: 258-267.

Bakken, A. J., S. C. Schoof, M. Bickerton, K. L. Kamminga, J. C. Jenrette, S. Malone, M. A. Abney, D. A. Herbert, D. Reisig, T. P. Kuhar, et al. 2015. Occurrence of brown marmorated stink bug (Hemiptera: Pentatomidae) on wild hosts in nonmanaged woodlands and soybean fields in North Carolina and Virginia. Environ. Entomol. 44: 1011-1021.

Bergmann, E. J., P. D. Venugopal, H. M. Martinson, M. J. Raupp, and P. M. Shrewsbury. 2016. Host plant use by the invasive Halyomorpha halys (Stål) on woody ornamental trees and shrubs. PLoS One 11: 1-12.

Boyle, S. M. 2017. Novel techniques for evaluating the potential host range of candidate biological control agent Trissolcus japonicus (Hymenoptera: Platygastridae). MS thesis. University of Delaware, Newark, DE.

Burks, B. D. 1967. The North American species of Anastatus Motschulsky (Hymenoptera, Eupelmidae). Trans. Am. Entomol. Soc. 93: 423-432.

Colazza, S., A. Cusumano, D. Lo Giudice, and E. Peri. 2014. Chemo-orientation responses in hymenopteran parasitoids induced by substrate-borne semiochemicals. BioControl. 59: 1-17.

Conti, E., and S. Colazza. 2012. Chemical ecology of egg parasitoids associated with true bugs. Psyche. 2012: 1-11.

Cornelius, M. L., C. Dieckhoff, K. A. Hoelmer, R. T. Olsen, D. C. Weber, M. V. Herlihy, E. J. Talamas, B. T. Vinyard, and M. H. Greenstone. 2016. Biological control of sentinel egg masses of the exotic invasive stink bug, Halyomorpha halys (Stål) in Mid-Atlantic USA ornamental landscapes. Biol. Control 103: 11-20.

Cottrell, T. E., C. E. Yonce, and B. W. Wood. 2000. Seasonal occurrence and vertical distribution of Euschistus servus (Say) and Euschistus tristigmus (Say) (Hemiptera: Pentatomidae) in pecan orchards. J. Entomol. Sci. 35: 421-431.

Dieckhoff, C., K. M. Tatman, and K. A. Hoelmer. 2017. Natural biological control of Halyomorpha hays by native egg parasitoids: a multi-year survey in northern Delaware. J. Pest Sci. 90: 1146-1158.

Herbert, D. A., Jr., K. Kamminga, S. Malone, T. P. Kuhar, E. Day, J. Greene, C. S. Bundy, L. Brown, and P. Ellsworth. 2014. Field guide to stink bugs of agricultural importance in the United States. Northeastern Integrated Pest Management Center, Ithaca, NY.VA Coop. Ext. Pub. No.VT/0914/444356/ ENTO-68. https://pubs.ext.vt.edu/444/444-356/444-356.html (accessed 12 march 2018).

Herlihy, M. V., E. J. Talamas, and D. C. Weber. 2016. Attack and success of native and exotic parasitoids on eggs of Halyomorpha halys in three maryland habitats. PLoS One 11: e0150275.

Hoebeke, E. R., and M. E. Carter. 2003. Halyomorpha halys (Stál) (Heteroptera: Pentatomidae): a polyphagous plant pest from Asia newly detected in North America. Proc. Entomol. Soc. Wash. 105: 225-237.

Huang, T. I., and M. D. Toews. 2012. Feeding preference and movement of Nezara viridula and Euschistus serous (Hemiptera: Pentatomidae) on individual cotton plants. J. Econ. Entomol. 105: 847-853.

Johnson, N. F. 1984. Systematics of Nearctic Telenomus: classification and revisions of the podisi and phymatae species groups (Hymenoptera: Scelionidae). Bull. Ohio Biol. Surv. 6: 1-113.

Joseph, S. V., J. C. Bergh, S. E. Wright, and T. C. Leskey. 2013. Factors affecting captures of brown marmorated stink bug, Halyomorpha halys (Hemiptera: Pentatomidae), in baited pyramid traps. J. Entomol. Sci. 48: $43-51$.

Joseph, S. V., J. W. Stallings, T. C. Leskey, G. Krawczyk, D. Polk, B. Butler, and J. C. Bergh. 2014. Spatial distribution of brown marmorated stink 
bug (Hemiptera: Pentatomidae) injury at harvest in mid-Atlantic apple orchards. J. Econ. Entomol. 107: 1839-1848.

Khrimian, A., A. Zhang, D. C. Weber, H. Y. Ho, J. R. Aldrich, K. E. Vermillion, M. A. Siegler, S. Shirali, F. Guzman, and T. C. Leskey. 2014. Discovery of the aggregation pheromone of the brown marmorated stink bug (Halyomorpha halys) through the creation of stereoisomeric libraries of 1-bisabolen-3-ols. J. Nat. Prod 77: 1708-1717.

Jones, A. L., D. E. Jennings, C. R. R. Hooks, and P. M. Shrewsbury. 2017. Field surveys of egg mortality and indigenous egg parasitoids of the brown marmorated stink bug, Halyomorpha halys, in ornamental nurseries in the mid-Atlantic region of the USA. J. Pest Sci. (2004). 90: 1159-1168.

Kowarik, I., and I. Säumel. 2007. Biological flora of Central Europe: Ailanthus altissima (Mill.) Swingle. Perspect. Plant Ecol. Evol. Syst. 8: 207-237.

Lee, D. H., and T. C. Leskey. 2015. Flight behavior of foraging and overwintering brown marmorated stink bug, Halyomorpha halys (Hemiptera: Pentatomidae). Bull. Entomol. Res. 105: 566-573.

Lee, D. H., A. L. Nielsen, and T. C. Leskey. 2014. Dispersal capacity and behavior of nymphal stages of Halyomorpha halys (Hemiptera: Pentatomidae) evaluated under laboratory and field conditions. J. Insect Behav. 27: 639-651.

Leskey, T. C., and A. L. Nielsen. 2018. Impact of the invasive brown marmorated stink bug in North America and Europe: history, biology, ecology, and management. Annu. Rev. Entomol. 63: 599-618.

Leskey, T. C., G. C. Hamilton, A. L. Nielsen, D. F. Polk, C. Rodriguez-Saona, J. C. Bergh, D. A. Herbert, T. P. Kuhar, D. Pfeiffer, G. P. Dively, et al. 2012 Pest status of the brown marmorated stink bug, Halyomorpha halys in the USA. Outlooks Pest Manag. 23: 218-226.

Leskey, T. C., A. Khrimian, D. C. Weber, J. C. Aldrich, B. D. Short, D. H. Lee, and W. R. Morrison, $3^{\text {rd }}$. 2015. Behavioral responses of the invasive Halyomorpha halys (Stål) to traps baited with stereoisomeric mixtures of 10,11-epoxy-1-bisabolen-3-OL. J. Chem. Ecol. 41: 418-429.

Martinson, H. M., P. D. Venugopal, E. J. Bergmann, P. M. Shrewsbury, and M. J. Raupp. 2015. Fruit availability influences the seasonal abundance of invasive stink bugs in ornamental tree nurseries. J. Pest Sci. 88: 461-468.

Morrison, W. R., $3^{\text {rd }}$, J. P. Cullum, and T. C. Leskey. 2015. Evaluation of trap designs and deployment strategies for capturing Halyomorpha halys (Hemiptera: Pentatomidae). J. Econ. Entomol. 108: 1683-1692.

Morrison, W. R., C. R. Mathews, and T. C. Leskey. 2016. Frequency, efficiency, and physical characteristics of predation by generalist predators of brown marmorated stink bug (Hemiptera: Pentatomidae) eggs. Biol. Control 97: 120-130.

Nielsen, A. L., and G. C. Hamilton. 2009. Life history of the invasive species Halyomorpha halys (Hemiptera: Pentatomidae) in northeastern United States. Ann. Entomol. Soc. Am. 102: 608-616.

Nielsen, A. L., S. Chen, and S. J. Fleischer. 2016. Coupling developmental physiology, photoperiod, and temperature to model phenology and dynamics of an invasive heteropteran, Halyomorpha halys. Front. Physiol. 7: 165.

Okuda, M. S., and K. V. Yeargan. 1988. Habitat partitioning by Telenomus podisi and Trissolcus euschisti (Hymenoptera: Scelionidae) between herbaceous and woody host plants. Environ. Entomol. 17: 795-798.
Owens, D. R., D. A. Herbert, T. Kuhar, and D. D. Reisig. 2013. Effects of temperature and relative humidity on the vertical distribution of stink bugs (Hemiptera: Pentatomidae) within a soybean canopy and implications for field sampling. J. Entomol. Sci. 48: 90-98.

Parker, G. G., M. D. Lowman, and N. M. Nadkarni. 1995. Forest canopies. Academic Press Inc., Cambridge, MA.

Peri, E., F. Frati, G. Salerno, E. Conti, and S. Colazza. 2013. Host chemical footprints induce host sex discrimination ability in egg parasitoids. PLoS One 8: e79054.

Rice, K., C. Bergh, E. Bergman, D. Biddinger, C. Dieckhoff, D. Dively, H. Fraser, T. Gariepy, G. Hamilton, and T. Haye. 2014. Biology, ecology, and management of brown marmorated stink bug (Halyomorpha halys). J. Integr. Pest Manag. 5: 1-13.

SAS Institute Inc. 2018. SAS software, version 9.4. The SAS Institute, Cary, NC.

Sivinski, J., M. Aluja, and M. Lopez. 1997. Spatial and temporal distributions of parasitoids of Mexican Anastrepha species (Diptera: Tephritidae) within the canopies of fruit trees. Ann. Entomol. Soc. Am. 90: 604-618.

Talamas, E. J., M. V. Herlihy, C. Dieckhoff, K. A. Hoelmer, M. Buffington, M-C. Bon, and D. C. Weber. 2015a. Trissolcus japonicus (Ashmead) (Hymenoptera, Scelionidae) emerges in North America. J. Hymenopt. Res. 43: 119-128.

Talamas, E. J., N. F. Johnson, and M. L. Buffington. 2015b. Key to Nearctic species of Trissolcus Ashmead (Hymenoptera, Scelionidae), natural enemies of native and invasive stink bugs (Hemiptera, Pentatomidae). J. Hymenopt. Res. 43: 45-110.

Tognon, R., J. Sant'Ana, Q. H. Zhang, J. G. Millar, J. R. Aldrich, and F. G. Zalom. 2016. Volatiles Mediating Parasitism of Euschistus conspersus and Halyomorpha halys Eggs by Telenomus podisi and Trissolcus erugatus. J. Chem. Ecol. 42: 1016-1027.

Venugopal, P. D., H. M. Martinson, E. J. Bergmann, P. M. Shrewsbury, and M. J. Raupp. 2015. Edge effects influence the abundance of the invasive Halyomorpha halys (Hemiptera: Pentatomidae) in Woody Plant Nurseries. Environ. Entomol. 44: 474-479.

Weber, D. C., T. C. Leskey, G. C. Walsh, and A. Khrimian. 2014. Synergy of aggregation pheromone with methyl $(E, E, Z)$-2,4,6-decatrienoate in attraction of Halyomorpha halys (Hemiptera: Pentatomidae). J. Econ. Entomol. 107: 1061-1068.

Wiman, N. G., V. M. Walton, P. W. Shearer, S. I. Rondon, and J. C. Lee. 2015. Factors affecting flight capacity of brown marmorated stink bug, Halyomorpha halys (Hemiptera: Pentatomidae). J. Pest Sci. 88: 37-47.

Yang, Z. Z-Q., Y. Y-X. Yao, L-F. L. Qiu, and Z. Z-X. Li. 2009. A new species of Trissolcus (Hymenoptera: Scelionidae) parasitizing eggs of Halyomorpha halys (Heteroptera: Pentatomidae) in China with comments on its biology. Ann. Entomol. Soc. Am. 102: 39-47.

Zhang, J., F. Zhang, T. Gariepy, P. Mason, D. Gillespie, E. Talamas, and T. Haye. 2017. Seasonal parasitism and host specificity of Trissolcus japonicus in northern China. J. Pest Sci. 90: 1127-1141. 